\title{
Parental Refusal of Pain Management: A Potentially Unrecognized Form of Medical Neglect
}

\author{
Robert C Macauley ${ }^{1 *}$ and Liberty J Fritzler ${ }^{2}$ \\ ${ }^{1}$ Department of Pediatrics, University of Vermont College of Medicine, USA \\ ${ }^{2}$ Department of Psychiatry, Henry Ford Hospital, USA
}

Received: December 11, 2013; Accepted: January 18, 2014; Published: January 20, 2014

*Corresponding author: Robert C Macauley, Department of Pediatrics, University of Vermont College of Medicine Smith 266, Fletcher Allen Health Care, 111 Colchester Ave, Burlington, VT 05401, USA, Tel: 802-847-2000; Fax: 802-847-2929; E-mail: robert.macauley@uvm.edu

\begin{abstract}
Medical neglect can have serious consequences for children, even leading to death. Yet while the American Academy of Pediatrics defines medical neglect in terms of a child who "is harmed or is at risk of harm because of lack of health care", in practice intervention is often limited to situations where the child's life is threatened. In this article we report a potentially unrecognized form of medical neglect-parental refusal of pain management-which does not affect the probability of the patient's survival, but does render inevitable a heightened degree of suffering and consequent psychological trauma. While it can be challenging to determine whether a specific refusal rises to the level of neglect, certain cases do meet the criteria of the "harm principle" and thus justify state intervention to protect the child.
\end{abstract}

Keywords: Neglect; Medical ethics; Pain management

\section{Abbreviations}

AAP: American Academy of Pediatrics; CPS: Child Protective Services; GBS: Guillain-Barre Syndrome; CAPTA: Child Abuse Prevention and Treatment Act; FLACC scale: Face, Legs, Activity, Cry, Consolability scale; IVIG: Intravenous Immune Globulin

\section{Case Presentation}

An eight-year-old boy was diagnosed with Guillain-Barre Syndrome (GBS), and his mother initially refused both intubation as well as intravenous immunoglobulin administration, based on her preference for "natural healing processes". Only after being informed that this would necessitate a report to Child Protective Services (CPS) did the mother begrudgingly give permission.

The patient's disease progressed to complete paralysis. His mother refused standard symptomatic treatment for an intubated patient (i.e., opioids and benzodiazepines) out of fear of addiction, preferring herbal and topical remedies which proved ineffective. The medical team listened to the mother's concerns at great length, and provided verbal and written education regarding the beneficial role of medication and the negligible risk of addiction for time-limited illness [1]. The father was enlisted as an advocate for the patient (the parents were divorced, and he lived with his mother and step siblings), and while the father was in favor of symptomatic treatment, he was not willing to defy his ex-wife. The Department of Spiritual Care was consulted to address spiritual issues impacting care, such as the mother's view of suffering as inevitable and redemptive. Despite maximal non-pharmacologic pain management, the patient began to experience severe neuropathic pain related to restore sensation. (Pain could not be assessed based on self-report because of maternal pressure on the patient, so a modified FLACC scale was used, taking into account the patient's inability to move his torso or extremities. Scores were consistently 5-6 on a six-point scale) [2].

A written plan was formulated in consultation with the family, which delineated between the "standard of care" (which would include opioid pretreatment for physical therapy and a scheduled analgesic targeting neuropathic pain) and optional treatments. Each of these steps followed the AAP stepwise response to perceived medical neglect [3].

The patient's mother continued to refuse any treatment for neuropathic pain, deeming that the side effects of the medications were too serious and arguing that the pain "would eventually go away on its own". The medical team was forced to make a report of medical neglect to CPS, whose initial response was to plan a home visit after discharge since the patient was "currently safe in the hospital". When made to understand that the patient was suffering in the hospital, CPS interviewed the parents at length. After the interview, the patient's mother who had been the subject of previous CPS reports was overheard by a nurse expressing her confidence that no action would be taken, since "they can't prove a greater than 50/50 chance of death."

Once CPS became involved, the patient's mother begrudgingly gave permission for Gabapentin to be started for neuropathic pain, although she continued to tell the patient that the doctors were "just trying to make you a zombie" and warned him that the medication could "make him want to kill himself". The consequent increase in the patient's anxiety and the inability to use medications that would have expeditiously addressed his symptoms led to a degree of suffering that was intensely difficult 
for the staff to watch (let alone for the patient to experience). In addition, after the patient developed a non-specific rashtemporally unrelated to the Gabapentin- the mother withdrew her permission for even this treatment.

The GBS eventually resolved and the patient was extubated. On the day of discharge, the reporting physician received a letter from CPS stating that there were insufficient grounds for further investigation of the report.

\section{Definition of Medical Neglect}

While competent adults have the right to refuse any medical treatment- even one that is life-sustaining [4] - pediatric decisionmaking is based on what is in the best interest of the child [5]. As famously phrased by the U.S. Supreme Court: "Parents may be free to become martyrs themselves, but it does not follow they are free, in identical circumstances, to make martyrs of their children before they have reached the age of full and legal discretion when they can make that choice for themselves" [6].

More specifically, medical neglect is defined by the Child Abuse Prevention and Treatment Act (CAPTA) as any "failure to act on the part of a parent or caretaker, which results in death, serious physical or emotional harm, sexual abuse or exploitation, or an act or failure to act which presents an imminent risk of serious harm" [7]. Beyond this general concept, each state is responsible for further defining neglect, and all states require physicians to report suspected neglect. The state of Vermont, where the case presented above occurred, defines a "neglected child" as "a child whose physical health, psychological growth and development or welfare is harmed or is at substantial risk of harm by the ... omissions of his or her parent" [8].

Recognizing that medical neglect can have serious consequences- even leading to death [9] - the American Academy of Pediatrics (AAP) has identified criteria for the diagnosis of neglect, as well as a stepwise response culminating in a report to CPS. Required diagnostic criteria include:

- "A child is harmed, or is at risk of harm for lack of healthcare;

- The recommended health care offers significant net benefit to the child;

- The anticipated benefit of the treatment is significantly greater than its morbidity, so that reasonable caregivers would choose treatment over non-treatment;

- It can be demonstrated that access to healthcare is accessible and not used; and

- The caregiver understands the medical advice given" [3].

Given this consistent emphasis on "harm" (or "risk of harm") in federal and state statutes, as well as the official position of the AAP- and acknowledging the extreme pain the young boy in this case experienced- how does one explain CPS' reluctance to intervene (or even initiate a full investigation)? And what steps can be taken in preventing children in similar situations from suffering, too?

\section{Why Refusal of Pain Management is Often not Recognized as Medical Neglect}

\section{Neglect is often framed in terms of survival}

Despite the emphasis on "harm" noted above, in practice- and, occasionally, in print- medical professionals and governmental organizations often frame neglect in terms of threat to life. For instance, while the AAP is clear that "it may be necessary to involve child protective services if the child is being harmed (or potentially harmed) by lack of medical care," at other points its recommendations regarding compulsory treatment focus on "the rights of seriously ill children to receive life-saving medical care even if their parents subscribe to religious beliefs that are antithetical to medical care" [3] emphasis added.Similarly, the word "martyr" (as often quoted from Prince v. Massachusetts) is often assumed to refer to someone who dies for their religious or political beliefs. It can, however, also apply to someone who "suffers a great deal, especially due to an illness" [10]. The patient in this case, even while recovering from his illness, clearly fits the latter description.

Another reason for often equating neglect with risk of death is that high-profile cases of potential medical neglect often involve both (potentially) curative as well as symptomatic treatment [11]. In such situations, the primary criterion for determining whether neglect has occurred is the parental refusal of "life-saving" treatment. Had the patient's mother in this case persisted in her refusal of intubation or IVIG administration, CPS would likely have substantiated the claim of medical neglect and authorized all necessary medical intervention, both curative and symptomatic. But since the patient's condition was no longer life-threatening, the refusal of symptomatic treatment alone was deemed insufficient evidence of neglect.

From the CPS perspective, focusing on threats to life may reflect the need to triage reports, with an emphasis on those which involve potential threats to life. In the U.S. in 2009, for instance, 3.3 million reports of child abuse or neglect were made to CPS involving approximately 6 million children. Approximately 2\% of these reports were for medical neglect, and only one out of six reports of maltreatment led to the conclusion that at least one child was a victim of abuse and/or neglect [12]. Given this vast scope of responsibility, it is understandable that CPS would prioritize threats to life, which may tragically result in underattention to potential harm through unmitigated suffering.

In light of the common practice of framing neglect in terms of survival, the mother's confidence that CPS would not intervene in a situation that was not life-threatening does not seem to be misplaced.

\section{Subjective nature of suffering}

Another reason for failing to intervene may be the subjective nature of suffering, and the resulting difficulty in determining whether a child is truly being harmed. It is a well-accepted tenet of pain management that pain is a subjective phenomenon [13]. Yet suffering is a much broader concept than physical pain, and 
in some cases pain may not be the cause of a patient's suffering (and thus analgesia would not be the appropriate response). By the same token, some patients in significant pain may not truly "suffer", by virtue of either the corollary benefits of experiencing such pain (as in the case of childbirth, for some laboring women) [14] or the potential drawbacks of treating the pain (as in the case of diminished lucidity in patients at the end of life) [15]. In this case, the gold standard for measuring pain (i.e., self-report) was confounded by maternal pressure, but objective measures consistently evidenced significant pain without any obvious compensatory benefit.

For all these reasons, the degree to which pain leads to suffering- and the degree to which suffering, in turn, represents harm- can be difficult to quantify. Some have taken this indeterminacy further, arguing that even if a certain degree of pain does constitute suffering, by virtue of its time- limited nature it doesn't actually constitute "harm". This view is misguided, however, given the multiple aspects of pain that are clearly harmful. The most obvious, of course, is that pain hurts, and most people take every possible step to avoid experiencing it. Beyond the present discomfort, untreated pain has been shown in the surgery literature, for instance, to cause significant morbidity via worsening the injury, preventing healing, causing infections, prolonging hospitalization, and even leading to death [1].

Repetitive stimulation of pain receptors also produces a "wind-up" phenomenon, such that subsequent painful stimuli evoke heightened responses, leading to Hyperalgesia and Allodynia [16,17]. Inadequate analgesia during painful procedures may change the "set-point" of children for future exposure to the same painful experience so that a child requires increased medication to control pain [18]. Such children are at increased risk of anxiety related to future procedures and may have negative perceptions of health care providers [1]. Studies have also shown a link between untreated pain and posttraumatic stress disorder [19-22], which would certainly seem to fit the definition of "emotional harm" in federal statute, as well as harm to "psychological welfare" in state law.

For these reasons, pain management has increasingly been classified as a basic human right [23]. The appropriate question, then, is not whether pain can constitute harm, but rather the nature, amount, and duration of pain that does constitute it.

At the same time, the potential for state intervention to worsen suffering needs to be considered. In this case, the option of simply going ahead and treating the pain over the parent's objectionbased on the standard of care and absent CPS authorization- was not a practical one, given that the mother was always present at the patient's bedside extolling the damage that analgesia could do to him. Unilateral overriding of her refusal could have worsened his overall suffering, and barring her access to the hospital would have left him isolated and alone. The only reasonable option to deferring to her refusal was a consolidated approach involving not only hospital staff but also state authorities.

\section{Various reasons for refusing analgesia}

Another challenge is the multiplicity of reasons which parents have for either not recognizing a child's pain and/or not providing treatment for it. In this case, distrust of the medical establishment and religious views were both factors in the mother's refusal of analgesia for her son. However, one should not assume that religious beliefs- some of which are clearly associated with refusal of both curative and symptomatic treatment of serious disease [9] - are the sole reason for refusal of pain management.

Recent studies have shown that a variety of factors play into parents' lack of recognition of their child's pain, including a sense that children may be exaggerating their pain or complaining to get attention, and a belief that children who are playing or are quiet cannot be in pain [24-31]. Hopefully discussion and education can counter these misperceptions, especially in cases as serious as the one presented here, where there are plentiful reports of the pain involved in GBS [32].

\section{Non-pharmacological options}

Even if one does recognize that a child is in pain, it is not entirely clear that pharmacologic treatment is indicated. Clearly there exists a wide variety of non-pharmacologic interventions for pain, which may well be effective and also avoid the side effects that come with any medical treatment [33]. Concern for such side effects- as well as for addiction and decreasing efficacy over time- has been shown to discourage parents from providing pain medications for their children [31]. Therefore, even if one grants that children in pain may be at risk of harm, the question of how to treat the pain remains to be answered.

\section{When Refusal of Pain Management does Constitute Medical Neglect}

As noted above, several issues complicate the determination of whether a parent's refusal of pain management truly constitutes medical neglect, including the practical focus on threat to life, the subjective nature of suffering, a potential lack of recognition of the existence and significance of pain, and competing methods for treating that pain. Given the complexity of the issue- and the multiplicity of potentially reasonable parental responses- it is helpful to reframe the issue in terms of the "Harm Principle" [34] (Table 1). For while the term "best interest" is used for the default decision-making paradigm in pediatrics [35], when

Table 1: Necessary conditions for state intervention in perceived medical neglect of a child [34].

\begin{tabular}{|l|l|}
\hline a) & Refusal places the child at significant risk of harm \\
\hline b) & The harm is imminent and requires immediate action to prevent it \\
\hline c) & The refused intervention is necessary to prevent the serious harm \\
\hline d) & $\begin{array}{l}\text { The refused intervention has proven efficacy and is likely to } \\
\text { prevent the harm }\end{array}$ \\
\hline e) & $\begin{array}{l}\text { The refused intervention does not place the child at significant } \\
\text { risk and the benefits outweigh the burdens }\end{array}$ \\
\hline f) & Potential less invasive alternatives have been considered \\
\hline g) & $\begin{array}{l}\text { The specific case considered can be generalized to all other similar } \\
\text { situations }\end{array}$ \\
\hline h) & Most parents would agree that the state intervention is reasonable \\
\hline
\end{tabular}


faced with several options parents are not required to choose the one the medical team feels is "best". Rather, the parents are simply required to choose among a range of acceptable options, specifically avoiding those that would cause the child harm.

The case presented here meets all eight requirements of the harm principle. Unmitigated severe pain represents imminent and significant harm to the child ( $\mathrm{a} \& \mathrm{~b}$ ), which can be ameliorated through pharmacologic means (d) that possess an excellent safety profile (e). Non-pharmacologic means were tried without success (f), and no other options were available (c). Concern for untreated extreme pain was not based on the parent's reasons for refusal, but rather on the risk of harm to the patient (g). And management of extremely burdensome symptoms has been identified as a moral imperative [36], one that presumably most parents would value sufficiently to favor state intervention on behalf of a child (h).

Given the greater latitude that parents are granted in decision-making (compared to other surrogates), the bar should be very high for requesting state intervention. The Harm Principle provides a reliable and demanding standard for CPS involvement, and only in rare and compelling cases- such as the one presented here- will every necessary condition be met.

\section{Conclusion}

In situations where the parent of a pediatric patient is refusing pain management, it is imperative to recognize that this may place the child at risk of undue psychological trauma, and thus also medical neglect. Once recognized, the step-wise approach set forth by the AAP for addressing situations of potential neglect is extremely helpful. This includes optimized communication, enhanced education, empathic listening, psychosocial support, and shared decision-making [3]. If this is unsuccessful in resolving the dilemma, next steps include objective assessment of the degree of pain and suffering, further exploration of the reasons for parental refusal, and exploration of non-pharmacologic interventions. Only when these are also unsuccessful- and all eight conditions of the Harm Principle are clearly met- is referral to CPS justified.

At that point it is important to emphasize to the CPS agency that while neglect is often framed in terms of threat to life, both legal statute (federal as well as state) and AAP policy affirm that risk of harm is the basis of neglect. The long-term sequelae of untreated pain- as well as the right of all persons to have their suffering addressed- should be stressed.

Practical obstacles (some of which are fairly unique to pain management) should also be highlighted, for while a child of Jehovah's Witnesses who has received a blood transfusion in the hospital could reasonably be deemed "safe," the same is not the case for a child in pain. Because pain is subjective- and typically measured by self-report- the potential for parental coercion (or at least discouragement of reporting pain) hampers adequate assessment and treatment. And because separation from a parent can cause significant suffering, the decision to intervene on the part of the state should never be taken lightly.
Because of the unique aspects of pain management noted above, it is critical for pediatricians to collaborate with- and educate- CPS personnel of the risk of harm posed by inadequate pain management, and the ethical justification in extreme cases such as this one for state intervention. Absent this, more children will be forced to suffer needlessly.

\section{References}

1. Schechter NL, Berde CB, Yaster M (2003) Pain in infants, children, and adolescents. ( $2^{\text {nd }}$ edn), Lippincott Williams \& Wilkins, Philadelphia, USA, pp. 892 .

2. Voepel-Lewis T, Zanotti J, Dammeyer JA, Merkel S (2010) Reliability and validity of the face, legs, activity, cry, consolability behavioral tool in assessing acute pain in critically ill patients. Am J Crit Care 19(1): 55-61.

3. Jenny C (2007) Recognizing and responding to medical neglect. Pediatrics 120(6): 1385-1389.

4. Cruzan v. Director (1990) Missouri Department of Health. S.Ct 2841, USA, pp. 261.

5. American Academy of Pediatrics (AAP) (1995) Informed consent, parental permission, and assent in pediatric practice. Committee on Bioethics, American Academy of Pediatrics. Pediatrics 95(2): 314-317.

6. Prince v. Massachusetts (1944) Supreme Court finds child protection laws, including vaccination, supersede parental religious freedom. In: Court USS, USA.

7. Child Abuse Prevention and Treatment Act. 42 USC 5101 et seq; 42 USC 5116 et seq.

8. Vermont Statute Title 33, § 4912 ("Reporting Abuse of Children")

9. Asser SM, Swan R (1998) Child fatalities from religion-motivated medical neglect. Pediatrics 101: 625-629.

10. Merriam-Webster's collegiate dictionary (2003) (11th edn), MerriamWebster, Inc., Springfield, MASS, USA.

11. Mercurio MR (2007) An adolescent's refusal of medical treatment: implications of the Abraham Cheerix case. Pediatrics 120(6): 1357-1358.

12.U.S. Department of Health and Human Services. Child Maltreatment 2010.

13. McGrath P, Gillespie J (2001) Pain assessment in children and adolescent. In: Turk DC \& Melzack R (Eds.), Handbook of pain assessment. ( $2^{\text {nd }}$ edn), Guilford Press, New York, USA, p. 15-34.

14. Lothian JA (2000) Why natural childbirth? J Perinat Educ 9(4): 44-46.

15. Steinhauser KE, Christakis NA, Clipp EC, McNeilly M, McIntyre L, et al. (2000) Factors considered important at the end of life by patients, family, physicians, and other care providers. JAMA 284(19): 2476-2482.

16. Taddio A, Chambers CT, Halperin SA, Ipp M, Lockett D, et al. (2009) Inadequate pain management during routine childhood immunizations: the nerve of it. Clin Ther 31(2): S152-167.

17. Walco GA, Cassidy RC, Schechter NL (1994) Pain, hurt, and harm. The ethics of pain control in infants and children. N Engl J Med 331(8): 541544

18. Weisman SJ, Bernstein B, Schechter NL (1998) Consequences of inadequate analgesia during painful procedures in children. Arch Pediatr Adolesc Med 152(2): 147-149.

19. Asmundson GJ, Coons MJ, Taylor S, Katz J (2002) PTSD and the experience of pain: research and clinical implications of shared vulnerability and 
mutual maintenance models. Can J Psychiatry 47(10): 930-937.

20. Asmundson GJ, Wright KD, Stein MB (2004) Pain and PTSD symptoms in female veterans. Eur J Pain 8(4): 345-50.

21. Sharp TJ, Harvey AG (2001) Chronic pain and posttraumatic stress disorder: mutual maintenance? Clin Psychol Rev 21(6): 857-877.

22. Taal LA, Faber AW (1997) Post-traumatic stress, pain and anxiety in adult burn victims. Burns 23(7-8): 545-549.

23. Brennan F, Carr DB, Cousins M (2007) Pain management: a fundamental human right. Anesth Analg 105(1): 205-221.

24. Finley GA, McGrath PJ, Forward SP, McNeill G, Fitzgerald P (1996) Parents' management of children's pain following 'minor' surgery. Pain 64(1): 83-87.

25. Fortier MA, MacLaren JE, Martin SR, Perret-Karimi D, Kain ZN (2009) Pediatric pain after ambulatory surgery: where's the medication? Pediatrics 124(4): e588-e595.

26. Hamers JP, Abu-Saad HH (2002) Children's pain at home following (adeno) tonsillectomy. Eur J Pain 6(3): 213-219.

27. Kankkunen P, Vehvilainen-Julkunen K, Pietila AM, Kokki H, Halonen P (2003) Parents' perceptions and use of analgesics at home after children's day surgery. Paediatr Anaesth 13(2): 132-140.

28. Munro HM, Malviya S, Lauder GR, Voepel-Lewis T, Tait AR (1999) Pain relief in children following outpatient surgery. J Clin Anesth 11(3):
187-91.

29. Warnock FF, Lander J (1998) Pain progression, intensity and outcomes following tonsillectomy. Pain 75(1): 37-45.

30. Wiggins SA, Foster RL (2007) Pain after tonsillectomy and adenoidectomy: "ouch it did hurt bad". Pain Manag Nurs 8(4): 156-165

31. Rony RY, Fortier MA, Chorney JM, Perret D, Kain ZN (2010) Parental postoperative pain management: attitudes, assessment, and management. Pediatrics 125(6): e1372-e1378.

32. Pentland B, Donald SM (1994) Pain in the Guillain-Barre syndrome: a clinical review. Pain 59(2): 159-64.

33. Kemper KJ, Vohra S, Walls R (2008) American Academy of Pediatrics. The use of complementary and alternative medicine in pediatrics. Pediatrics 122(6): 1374-1386.

34. Diekema DS (2004) Parental refusals of medical treatment: the harm principle as threshold for state intervention. Theor Med Bioeth 25(4): 243 264.

35. Beauchamp TL, Childress JF (2009) Principles of biomedical ethics. $\left(6^{\text {th }}\right.$ edn), Oxford University Press New York, USA.

36. Berlinger N, Jennings B, Wolf SM (2013) The Hastings Center guidelines for decisions on life-sustaining treatment and care near the end of life. Revised and expanded. (2 ${ }^{\text {nd }}$ edn), Oxford University Press, New York, USA. 